\title{
SISTEM INFORMASI PENJUALAN MAKANAN OLAHAN BERBASIS WEB PADA TOKO ANYAR BEKASI
}

\author{
Nandang Iriadi ${ }^{1}$ \\ ${ }^{1}$ Program Studi Teknik \\ Komputer Akademi Bina \\ Sarana Informatika Komputer \\ AMIK BSI Jakarta \\ nandang.ndi@bsi.ac.id
}

\author{
Priatno $^{2}$ \\ ${ }^{2}$ Program Studi Periklanan \\ Akademi Bina Sarana \\ Informatika AKOM BSI \\ Jakarta \\ priatno.prn@bsi.ac.id
}

\author{
Sainan3 \\ ${ }^{3}$ Program Studi Sistem \\ Informasi STMIK Nusa \\ Mandiri Jakarta \\ saenan.bj_enesis@yahoo.com
}

\begin{abstract}
Abstrak - Toko Anyar merupakan salah satu perusahaan penjualan makanan instant (siap saji) yang berada di daerah Bekasi. Pada Toko Anyar tersebut penulis melakukan analisa sistem penjualan yang sedang berjalan saat ini. Penjualan yang dilakukan diperusahaan ternyata masih kurang mendapatkan pendapatan yang maksimal. Income yang tidak tentu, kurangnya promosi dan menjadikan Toko Anyar belum dikenal dikalangan masyarakat luas. Desain penelitian yang digunakan adalah bersifat deskriptif dengan pendekatan studi kasus pada Toko Anyar. Metode pendekatan yang digunakan terstuktur dan metode pengembangan sistem informasi penjualan
\end{abstract}

\section{PENDAHULUAN}

Persaingan usaha yang ketat dewasa ini mengharuskan perusahaan untuk berfokus kepada kebutuhan yang diinginkan oleh konsumen. Perusahaan mulai mengubah pola piker dari orientasi keuntungan kearah faktorfaktor potensial lainnya seperti kepentingan pelanggan dan tingkat kepuasan pelanggan menjadi factor utama yang harus diperhatikan oleh perusahaan. Kondisi persaingan bisnis yang terjadi pada saat sekarang ini membuat perusahaan harus menyadari dengan cermat target pasar yang ditujunya dan tingkat kualitas produk atau jasanya. Selain itu, factor penting yang harus dipertimbangkan oleh perusahaan dalam menghadapi persaingan bisnis adalah tingkat value yang mampu diberikan kepada pelanggan dan cara memperlakukan pelanggan dari hari ke hari. Beberapa riset yang telah dilakukan, menunjukkan bahwa dalam strategi bisnis mempertahankan pelanggan lama lebih menguntungkan daripada menarik pelanggan baru.

Sekarang ini, perkembangan usaha di Indonesia sudah semakin berkembang terlebih berbasis web. Hasil penelitian menunjukan bahwa perancanagan sistem informasi penjualan dan pemesanan berbasis web dapat membatu konsumen dalam mengakses informasi mengenai produk yang dijual dan dalam melakukan pemesanan produk, mengimplementasikan sistem informasi yang meliputi implementasi perangkat lunak, perangkat keras, basis data antarmuka dari aplikasi yang dihasilkan. Tahap akhir adalah mengadakan pengujian terhadap aplikasi. Kata Kunci : Toko Anyar, Web

jenis usaha kuliner (makanan dan minuman) seperti jenis usaha makanan beku siap saji.

Namun, saat ini Toko Anyar Bekasi tidak memiliki aktifitas atau strategi khusus yang menangani pemasaran, pemasaran produk dilakukan secara konvensional dengan cara pelanggan memberikan informasi mengenai tempat, keistimewaan dan produk ke calon pelanggan lain. Dengan pemasaran seperti ini, menyebabkan peluang untuk mendapatkan calon pelanggan secara maksimal tidak terpenuhi dan hal ini sangat disayangkan mengingat produk makanan beku sudah dikenal diberbagai kalangan menengah keatas maupun menengah kebawah. Penyebaran informasi yang tidak efektif membuat pelanggan tidak mengetahui informasiinformasi terbaru sehingga mempengaruhi pelanggan lain untuk beralih ke toko lain.

Sistem pemasaran yang telah dijelaskan sebelumnya menyebabkan pemilik usaha harus berlomba dengan pesaingnya untuk mendapatkan pelanggan baru sebanyakbanyaknya dan mempertahankan pelanggan lama dengan menjalin komunikasi yang baik dan berkesinambungan. Selain itu, semakin berkembangnya usaha makanan beku tentu 
saja membuat tingkat persaingan menjadi lebih tinggi sehingga membuat pemilik usaha harus mencari strategi bisnis yang tepat dalam menghadapi persaingan bisnis ini agar dapat mempertahankan pelanggannya dan meningkatkan penjualannya. Pelanggan yang loyal merupakan cermin dari kepuasan pelanggan, dimana pada saat ini harga tidak menjadi factor yang utama bagi mereka, namun menjadi sesuatu yang relative.

Di era globalisasi ini banyak media yang menyajikan informasi tentang kuliner, tetapi hamper dari semua yang disajikan itu belum berbasis web. Yang beredar dipasaran biasanya dalam bentuk media cetak (Koran, majalah, tabloid, dll).

Seiring berjalannya zaman dan kemajuan teknologi yang dari hari ke hari semakin cepat, hal ini memacu untuk membuat suatu aplikasi yang bisa diakses secara online mengenai informasi penjualan makanan beku secara online. Sehingga mudah untuk diakses kapan saja dan dimana saja tentunya yang lebih efektif dan efesien.

\section{METODELOGI PENELITIAN}

Suatu penelitian dikatakan sebagai penelitian apabila kegiatan tersebut merupakan suatu usaha yang sistematis dan terorganisir untuk menyelidiki masalah tertentu yang memerlukan jawaban. Jenis penelitian ini adalah penelitian eksploratif dengan pendekatan kualitatif.

Dalam penelitian ini peneliti akan menggali data dari dua sumber data yaitu primer dan sekunder, adapun yang dijadikan sumber data primer yaitu data yang diperoleh melalui pengamatan secara langsung dari sumbernya, yaitu lingkungan Toko Anyar Bekasi sebagai objek penelitian. Dalam penelitian ini data primer diperoleh dari informan: (pemilik toko dan pegawai toko), data usaha, dan sumber data sekunder yaitu data - data yang diperoleh melalui pengamatan literature, dokumen-dokumen dan lain sebagainya, yang berhubungan dengan masalah yang diteliti.

Teknik pengumpulan data yang digunakan oleh peneliti adalah riset lapangan yang meliputi : observasi, wawancara dan studi pustaka. Pengamatan secara langsung keobjek yang mau diteliti dalam hal ini yaitu Toko Anyar Bekasi yang sedang diadakan penelitian. Observasi dilakukan selama kurang lebih 30 hari yaitu dengan menganalisa terhadap jalannya sistem serta aspek - aspek lain yang dapat mempengaruhi jalannya sistem baik dari sisi lingkungan maupun dari sisi pengguna sistem itu sendiri.
Selain observasi, wawancara juga dilakukan untuk melengkapi data yang dibutuhkan. Wawancara dilakukan kepada pemilik dan staff Toko Anyar Bekasi untuk mencari data mengenai kekurangan dari sistem yang sedang berjalan serta kebutuhan - kebutuhan lain yang diperlukan yang belum tercukupi dari sistem yang telah ada sekarang.

Kepustakaan dilakukan untuk menunjang metode wawancara dan observasi yang telah dilakukan. Pengumpulan informasi yang dibutuhkan dilakukan dengan mencari referensi - referensi yang berhubungan dengan penelitian yang dilakukan, referensi dapat diperoleh dari buku - buku atau internet.

Sedangkan untuk model pengambangan sistem yang digunakan oleh peneliti yaitu meliputi : Analisa kebutuhan software, Desain, Code Generation, Testing dan Support.

Analisa kebutuhan software yaitu menganalisa dan mendefenisikan masalah dan kemungkinan solusinya untuk proses suatu informasi agar menjadi lebih terstruktur.

Desain yaitu Pada tahap ini penulis merancang design dan pembuatan program dengan ERD (Entity Relationship Diagram), Diagram UML (Unitefed Modeling Language) yang digunakan yaitu Use Case Diagram, Activity Diagram, Component Diagram dan Deployment Diagram.

Code Generation yaitu Tahapan pembuatan program menggunakan bahasa pemrograman CSS (Cascading Style Sheet), PHP, MySQL maupun HTML (Hyper Text Markup Language). Teknik pemrograman yang digunakan yaitu pemrograman terstruktur.

Testing yaitu Pengujian perangkat lunak yaitu dengan menggunakan metode blackbox testing. Metode uji coba blackbox testing memfokuskan keperluan fungsional dari software. Uji coba blackbox testing berusaha menemukan kesalahan dalam fungsi-fungsi yang salah atau hilang.

Support yaitu Dalam tahap ini penulis menggunakan hardware dengan spesifikasi operating system windows 7 ultimate 32-bit (6.1, build 7601). Processor AMD E1-1200 APU Atom (TM) with Radeon (tm) HD Graphics (2 CPUs), 1.4GHz, RAM (Random Access Memory) 2GB, Harddisk 300GB dan software pendukung seperti Macromedia Dreamweaver, PhotoShop serta membutuhkan hosting domain.

\section{DASAR TEORI}

\section{E-Commerce}

E-Commerce dapat diartikan sebagai suatu proses berbisnis dengan menggunakan teknologi elektronik yang menghubungkan antara perusahaan, konsumen dan masyarakat dalam bentuk transaksi elektronik dan 
pertukaran/penjualan barang, servis, dan informasi secara elektronik (Munawar,2009:1).

\section{Unitefed Modeling Language (UML)}

Menurut Widodo, (2011:6), "UML adalahApache2triad bahasa pemodelan standart yang memiliki sintak dan semantik".

Menurut Nugroho (2010:6), "UML (Unified Modeling Language) adalah bahasa pemodelan untuk sistem atau perangkat lunak yang berparadigma (berorientasi objek)."

\section{Entity Relationship Diagram (ERD)}

Menurut Fitriasari (2009:92), "ERD adalah suatu grafis yang menggambarkan suatu skema database".

Dari definisi tersebut dapat disimpulkan bahwa Entity Relationship Diagram (ERD) merupakan suatu grafis yang menggambarkan suatu skema database.

\section{E. Hypertext Preprocessor (PHP)}

Hypertext Preprocessor yaitu bahasa pemrograman web server-side yang bersifat open source. PHP merupakan script yang terintegrasi dengan HTML dan berada pada server (server side HTML embedded scripting). PHP adalah script yang digunakan untuk membuat halaman website yang dinamis. Dinamis berarti halaman yang akan ditampilkan dibuat saat halaman itu diminta oleh client. Mekanisme ini menyebabkan informasi yang diterima client selalu yang terbaru/up to date. Semua script PHP dieksekusi pada server dimana script tersebut dijalankan. (Anhar, 2010:3)

\section{F. My Structured Query Language (MySQL)}

Menurut Kurniawan dkk (2011:12), SQL (Structured Query Language) adalah sebuah bahasa yang dipergunakan untuk mengakses data dalam basis data relasional. SQL juga dapat diartikan sebagai antar muka standar untuk sistem manajemen basis data relasional, termasuk sistem yang beroperasi pada komputer pribadi. SQL memungkinkan seorang pengguna untuk mengakses informasi tanpa mengetahui dimana lokasinya atau bagaimana informasi tersebut disusun.
Menurut Sutisna (2007:48) “Apache2triad adalah penyempurnaan dari PHP Triad, yaitu software open source yang merupakan gabungan dari beberapa software pendukung web". Pada Apache2triad, server Apache, PHP dan database MySQL dikemas dalam satu paket sehingga lebih memudahkan Perl, Phyton dan beberapa bahasa pemograman lainnya. Apache2triad menyertakan PhpMyAdmin. Apache2triad dapat dijalankan pada sistem operasi unix/linux, Windows $9 X /$ Windows $X P$.

\section{Adobe Dreamweaver}

Menurut Sigit (2010:1), “Dreamweaver adalah sebuah HTML editor profesional untuk mendesain web secara visual dan mengelola situs atau halaman web".

\section{Logical Record Structure (LRS)}

Menurut Kroenke (2006:76) mengemukakan bahwa "Logical Record Structure" (LRS) adalah representasi dari struktur recordrecord pada tabel-tabel yang terbentuk dari hasil relasi antar himpunan entitas. Dibentuk dengan nomor dan tipe record. Beberapa tipe record digambarkan oleh kotak empat persegi panjang dan dengan nama yang unik. Perbedaan LRS dan ERD adalah nama dan tipe record berada diluar field tipe record di tempatkan. LRS terdiri dari link-link diantara tipe record. Link ini menunjukkan arah dari satu tipe record lainnya. Banyak link dari LRS yang diberi tanda field-field yang kelihatan pada kedua link tipe record. Penggambaran LRS mulai dengan menggunakan model yang dimengerti. Dua metode yang digunakan, dimulai dengan hubungan kedua model yang dapat dikonversikan ke LRS.

\section{TEKNIK PENGUMPULAN DATA}




\section{Observasi}

Penulis melakukan pengamatan langsung ke Toko Anyar dan tinjauan langsung terhadap website-website di internet yang berhubungan dengan objek penelitian.

\section{Wawancara}

Penulis melakukan wawancara secara langsung serta mengajukan pertanyaan-pertanyaan kepada pemilik dan beberapa pegawai karyawan pada Toko Anyar.

\section{Studi Pustaka}

Penulis juga mengumpulkan data melalui buku bacaan, internet, dan sumber lainnya yang erat kaitannya dengan tema penulisan untuk melengkapi dan menyempurnakan data yang ada.

\section{ANALISA KEBUTUHAN}

Spesifikasi Hardware dan Software

Tabel IV.23.

Spesifikasi Hardware dan Software

\begin{tabular}{|c|c|}
\hline Kebutuhan & Keterangan \\
\hline Sistem Operasi & Windows 7 ultimate 32-bit $(6.1$, build \\
\hline Processor & $\begin{array}{l}\text { AMD E1-1200 APU Atom (TM) with } \\
\text { Graphics (2 CPUs), } \sim 1.4 \mathrm{GHz}\end{array}$ \\
\hline RAM & $2 \mathrm{~GB}$ \\
\hline Hard Disk & $300 \mathrm{~GB}$ \\
\hline Monitor & LCD \\
\hline Keyboard & Keyboard Standard $\mathrm{PS} / 2$ \\
\hline Printer & Inkjet \\
\hline Mouse & Mouse Optic \\
\hline Browser & Mozilla Firefox \\
\hline Software & Dreamweaver, Photoshop,Php MyAdn \\
\hline
\end{tabular}

\section{ANALISA PENGGUNA}

\section{Owner}

Merupakan orang yang memimpin pelaksanaan kegiatan perusahaan, tugasnya adalah mengendalikan jalannya perusahaan atau bertugas sebagai pengelola segala kegiatan perusahaan.

\section{Bagian Penjualan}

barang beserta dengan detail harganya kepada konsumen, mencatat pemesanan barang, dan membuat laporan penjualan kepada owner.

\section{Bagian Pengiriman}

Melakukan pengiriman barang dengan cepat ke alamat tujuan customer.

Toko Anyar adalah toko yang bergerak dalam bidang penjualan makanan olahan beku. Aktivitas sistem berjalan dimulai dari customer datang langsung ke toko, melihat produk, dan menanyakan informasi barang. Customer melakukan pemesanan kemudian melakukan pembayaran bagian penjualan akan membuatkan kwitansi untuk customer. Bagian penjualan memberikan surat jalan ke bagian pengiriman untuk segera mengirimkan barang pesanan customer. Bagian penjualan membuat laporan penjualan selama satu bulan lalu diserahkan kepada owner.

Sistem informasi penjulalan berbasis web sebagai media promosi dan komunikasi dimana penjual dan customer tidak bertatap muka secara langsung. Customer melakukan pembelian dengan menggunakan media browser dan internet lalu mengakses website www.tokoanyar.com. Customer dapat melihat produk-produk yang tersedia di halaman website. Berikut adalah spesifikasi dari sistem penjualan online yang penulis usulkan.

Sistem Informasi Penjualan Makanan Olahan Beku Berbasis Web Pada Toko Anyar Bekasi. Calon member melakukan pembelian melalui media browser. Berikut ini adalah spesifikasi kebutuhan (system requitment) dari sistem $e$ commerce.

\section{perusahaan.}

A1. User dapat melihat profil

A2. User dapat melihat produk yang dijual.

A3. User dapat melihat cara pesan.

A4. User dapat melihat kontak perusahaan.

A5. User dapat mengisi buku tamu. 
Halaman Customer:

B1. Customer dapat melihat-lihat produk serta detail informasi dari suatu produk.

B2. Customer memilih barang yang akan dibeli dan ditambahkan ke keranjang belanja.

B3. Customer dapat memfilter pencarian produk berdasarkan kategori.

B4. Sistem melakukan pengecekan apakah customer tersebut telah menjadi member di website.

B5. Customer yang belum terdaftar sebagai member dapat melakukan registrasi terlebih dahulu.

B6. Customer yang telah terdaftar dapat login

dengan akun yang telah dibuat apabila ingin

belanja dilain hari.

B7. Sistem melakukan konfirmasi pembayaran.

Halaman Administrasi:

C1. Admin harus login terlebih dahulu untuk mengelola website.

C2. Admin dapat mengelola manajemen

modul. produk.

C3. Admin dapat mengelola data

C4. Admin dapat mengelola kategori.

C5. Admin dapat mengelola data pemesanan. kirim.

C6. Admin dapat mengelola ongkos

C7. Admin dapat mengelola profil.

Berikut adalah Use Case Diagram Belanja Online Halaman Customer :

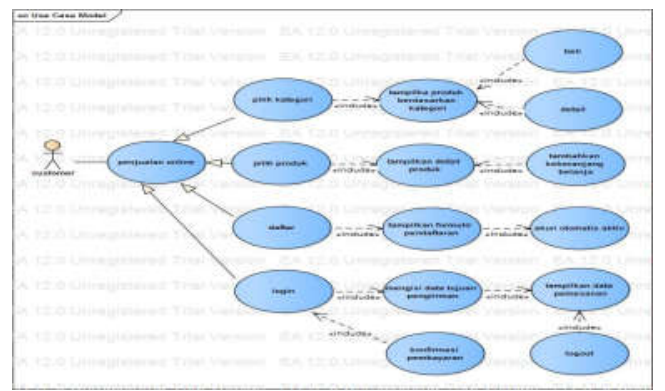

Gambar 2. Use Case Diagram Belanja Online Halaman Customer.

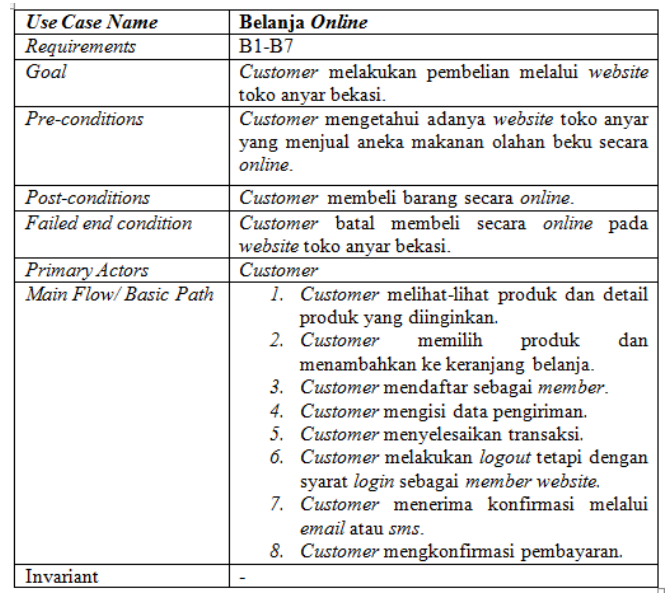

Tabel 1. Deskripsi Use Case Diagram Belanja Online Halaman Customer.

Berikut adalah Use Case Diagram Penjualan Online Halaman Administrator :

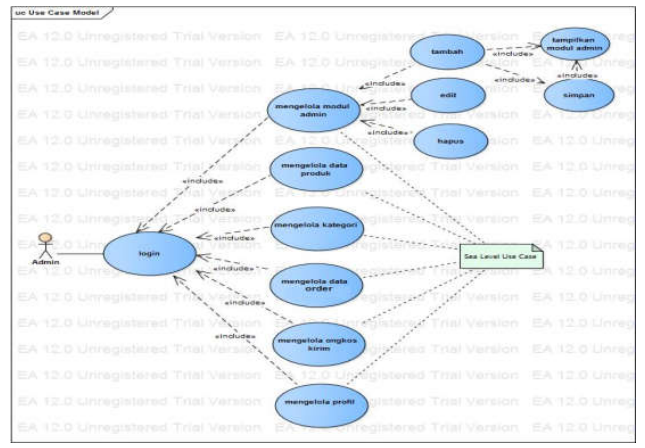

Gambar 3. Use Case Diagram Penjualan Online Halaman Administrator

Implementasi Sistem adalah langkah-langkah atau prosedur-prosedur yang dilakukan dalam menyelesaikan desain sistem yang telah disetuujui, meliputi penyiapan peralatan, penyusunan program, pelatihan karyawan, penyiapan dan uji coba sistem yang diperbaiki untuk menggantikan sistem yang lama.

Berikut adalah beberapa contoh tampilan program Toko Anyar Bekasi :

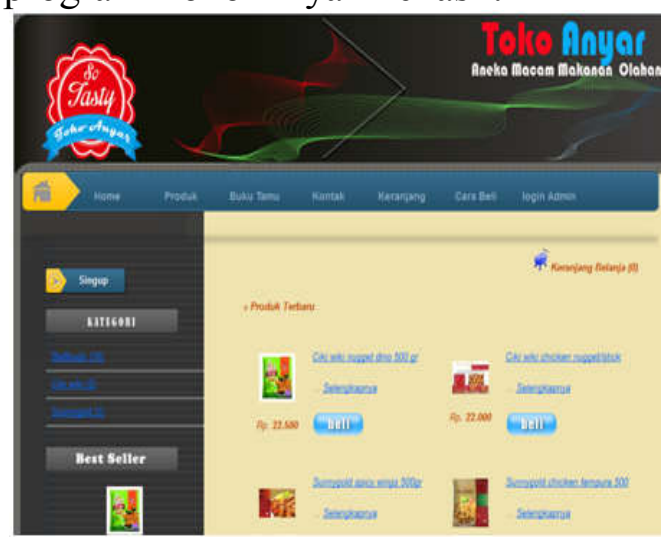




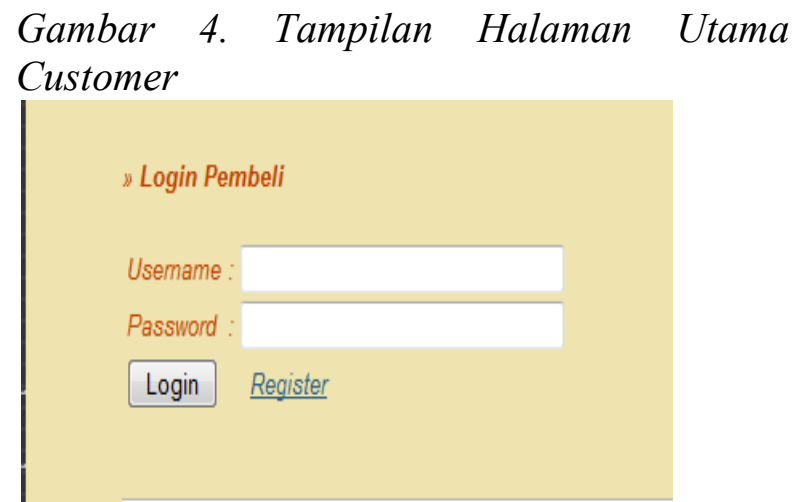

Gambar 5. Tampilan Halaman Login Member

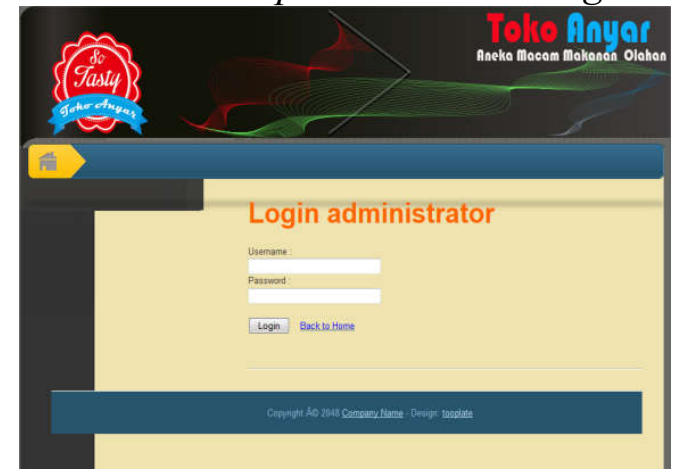

Gambar 6. Tampilan Halaman Login Administrator

\section{SIMPULAN}

a) Dengan mengembangkan sistem informasi berbasis web, diharapkan pemasaran produk menjadi lebih maksimal.

b) Dengan adanya web Toko Anyar Bekasi dapat meningkatkan penjualan dan kepuasan pelanggan.

\section{Saran :}

Diharapkan agar sistem harus sering dimaintance dan sistem dikembangkan lagi, agar medapatkan hasil yang lebih maksimal dari sebelumnya

\section{DAFTAR PUSTAKA}

Aan Tri Wibowo. (2013). Pembuatan Aplikasi ECommerce Pusat Oleh-Oleh Khas Pacitan Pada Toko Sari Rasa Pacitan. ISSN: 2302-5700. Pacitan: IJNS (Indonesian Journal on Networking and Security) Volume 2 No 4 Oktober 2013. Diambil dari : http://ijns.org/journal/index.php/ijns/article/vie $\mathrm{w} / 247$.

Anhar. (2010). Panduan Menguasai PHP dan Mysql. Jakarta: Media Kita.

Christianus, Sigit. (2010). Pengantar Manajemen Proyek Berbasis Internet. Jakarta: PT. Elex Media Komputindo.

Gaol, Jimmy L. (2008). Sistem Informasi Menejemen Pemahaman dan Aplikasi. Jakarta: Grasindo.

Hendra Kurniawan, Eri Mardiani, dan Nur Rahmansyah. (2011). Aplikasi Penjualan dengan Program Java Netbeans, Xampp, dan iReport. Jakarta: PT. Gramedia Pustaka Utama.

Herlawati, dan Prabowo Pudjo Widodo. (2011). Menggunakan UML. Bandung: Informatika.

Mulyanto, Agus. (2009). Sistem Informasi Konsep dan Aplikasi. Yogyakarta: Pustaka Pelajar.

Munawar, Kholil. (2009) E-commerce. http://staff.uns.ac.id.

Ovi Dyantina, Mira Afrina dan Ali Ibrahim. (2012). Penerapan Customer Relationship Management (CRM) Berbasis Web (Studi Kasus Pada Sistem Informasi Pemasaran di Toko YEN-YEN). ISSN Print: 2085-1588, ISSN Online: 23554614. Sumatra Selatan: Jurnal Sistem Informasi (JSI), Vol. 4, No. 2, Okotober 2012. Diambil dari:

http://ejournal.unsri.ac.id/index.php/jsi/index.

Puji Susanto dan Irma Puspita Sari. 2012. Pembangun Perangkat Lunak AplikasiResep Hidangan Berbasis Web. Bandung. Jurnal LPKIA, Vol.1No.2, Desember 2012. Diambil dari http://ejournal.lpkia.ac.id/files/students/essays/j ournals/408.pdf.

Sutisna, Dadan. (2007). 7 Langkah Mudah menjadi Webmaster. Jakarta Selatan: Media Kita.

Wong, Jony. (2010). Internet Marketing for Beginners. Jakarta: Elex Media Komputindo 